\title{
(2) OPEN ACCESS \\ Evaluating the impact of menthol cigarette bans on cessation and smoking behaviours in Canada: longitudinal findings from the Canadian arm of the 2016-2018 ITC Four Country Smoking and Vaping Surveys
}

\author{
Janet Chung-Hall (1) , ${ }^{1}$ Geoffrey T Fong 지 1,2,3 Gang Meng, ${ }^{1}$ \\ K Michael Cummings ${ }^{\circ},{ }^{4}$ Andrew Hyland, ${ }^{5}$ Richard J O'Connor, ${ }^{5}$ \\ Anne C K Quah (1) , ${ }^{1}$ Lorraine V Craig (1) ${ }^{1}$
}

- Additional material is published online only. To view please visit the journal online (http://dx.doi.org/10.1136/ tobaccocontrol-2020-056259).

${ }^{1}$ Psychology, University of Waterloo, Waterloo, Ontario, Canada

${ }^{2}$ School of Public Health and Health Systems, University of Waterloo, Waterloo, Ontario, Canada

${ }^{3}$ Ontario Institute for Cancer Research, Toronto, Ontario, Canada

${ }^{4}$ Psychiatry \& Behavioral Sciences, Medical University of South Carolina, Charleston, South Carolina, USA ${ }^{5}$ Health Behavior, Roswell Park Comprehensive Cancer Center, Buffalo, New York, USA

\section{Correspondence to} Dr Janet Chung-Hall, Psychology, University of Waterloo, Waterloo, Canada; jchunghall@uwaterloo.ca

Received 24 September 2020 Revised 6 March 2021 Accepted 13 March 2021
Check for updates

(c) Author(s) (or their employer(s)) 2021. Re-use permitted under CC BY-NC. No commercial re-use. See rights and permissions. Published by BMJ.

To cite: Chung-Hall J, Fong GT, Meng G, et al. Tob Contro/ Epub ahead of print: [please include Day Month Year]. doi:10.1136/ tobaccocontrol-2020-056259

\section{ABSTRACT}

Objective To evaluate the impact of menthol cigarette bans in seven Canadian provinces between 2016 and 2018.

Methods Longitudinal data from the Canadian arm of the 2016 and 2018 ITC Four Country Smoking and Vaping Survey. 1098 non-menthol and 138 menthol smokers were surveyed pre-menthol and post-menthol cigarette bans. Multivariate logistic regression models examined associations between pre-post ban changes in smoking behaviour, including differences between menthol and non-menthol smokers in quit attempts and quitting.

Results At follow-up, 59.1\% of pre-ban menthol smokers switched to non-menthol cigarettes; $21.5 \%$ quit smoking and $19.5 \%$ still smoked menthols, primarily purchased from First Nations reserves. Menthol smokers were more likely than non-menthol smokers to make a quit attempt (adjusted OR (aOR)=1.61, 95\% Cl 1.03 to 2.51$)$, and to remain quit $(\mathrm{aOR}=2.30,95 \% \mathrm{Cl} 1.06$ to 5.01). Menthol smokers did not differ significantly from non-menthol smokers in quit success $(\mathrm{aOR}=1.72$, $95 \% \mathrm{Cl} 0.98$ to 3.01); however, daily menthol smokers were more likely than daily non-menthol smokers to quit $(\mathrm{aOR}=2.21,95 \% \mathrm{Cl} 1.15$ to 4.24$)$, and daily menthol smokers who quit before the ban were more likely than daily non-menthol smokers to remain quit ( $\mathrm{aOR}=2.81$, $95 \%$ Cl 1.15 to 6.85 ).

Conclusions Although menthol smokers were most likely to switch to non-menthol cigarettes, the menthol ban was also significantly associated with higher rates of quit attempts and quit success among menthol smokers compared with non-menthol smokers, and may have helped to prevent relapse among menthol smokers who had quit smoking before the ban. Results confirm and extend evaluation of Ontario's menthol ban across provinces covering $83 \%$ of the Canadian population.

\section{INTRODUCTION}

Menthol was first added as a characterising flavour to cigarettes in the USA in the 1920s, and is still the most common flavouring for cigarettes in many countries. ${ }^{1-3}$ Menthol creates a cooling sensation that reduces the harshness of cigarette smoke, ${ }^{45}$ thereby leading to increased experimentation and progression to regular smoking among new smokers, especially those who are younger. ${ }^{67}$

Independent scientific reviews conducted by the Tobacco Products Scientific Advisory Committee, ${ }^{2}$ the US Food and Drug Administration ${ }^{8}$ and the WHO Study Group on Tobacco Product Regulation $^{9}$ have all concluded that the removal of menthol from cigarettes would have significant public health benefits, and recommended a ban on menthol cigarettes.

Canada was one of the first countries in the world to introduce bans on menthol cigarettes. Between May 2015 and July 2017, 7 out of 10 Canadian provinces implemented menthol cigarette bans. ${ }^{10}$ A federal ban on menthol (including all analogues and derivatives) in cigarettes, most cigars and blunt wraps came into force in October 2017. ${ }^{11}$ Nationwide menthol cigarette bans have also been implemented in Ethiopia (September 2015), Senegal (May 2017), Uganda (September 2019), Nigeria (April 2020), Moldova (May 2020), Turkey (May 2020) and the European Union (May 2020).

Researchers have used different methods to evaluate the potential impact of a menthol cigarette ban, including surveys to assess smokers' intended behaviour in response to a hypothetical menthol ban, simulation modelling and experimental switching of menthol smokers to non-menthol cigarettes. $^{12-14}$ However, few population-level studies have evaluated the actual effects of implemented menthol cigarette bans.

Research from the Canadian province of Ontario provides the best available evidence for the public health impact of a real-world menthol cigarette ban to date. After Ontario banned menthol cigarettes, sales of menthol cigarettes and all cigarettes in Ontario declined to approximately zero and by $11 \%$, respectively, compared with no changes in British Columbia (no provincial menthol ban). ${ }^{15}$ Daily menthol smokers in Ontario were also more likely than non-menthol smokers to make quit attempts $(63.0 \%$ vs $43.0 \%)$ and quit smoking $(24.0 \%$ vs $14.0 \%)$ after the ban. ${ }^{16}$ Another study found that $29.1 \%$ of menthol smokers made a post-ban quit attempt. ${ }^{17}$ Some studies have found that menthol smokers switched to other products. 
One study found that $29.0 \%$ of menthol smokers reported using other flavoured tobacco or e-cigarettes after Ontario's menthol cigarette ban. ${ }^{17}$ Another Ontario study found that daily menthol cigarette smokers were more likely to use other tobacco products, flavoured tobacco products and flavoured cigars after a menthol cigarette ban. ${ }^{18}$

An important design element of a 2019 evaluation of Ontario's 1 January 2017 menthol ban on smoking cessation was the comparison of menthol smokers to non-menthol smokers. ${ }^{16}$ This study controlled for the potential influence of two eventsNew Year's resolutions and National Non-Smoking Week in Canada-which are both known to increase quitting. ${ }^{19} 20$ The present study examined the impact of a menthol cigarette ban in Ontario, but also in six other provinces, where bans were implemented at other times of the year, thereby allowing for policy evaluation across a broader range of Canadian provinces and implementation dates than the January implementation in Ontario.

Evaluating the impact of a menthol ban is critical to inform regulatory actions that would maximise public health benefits and minimise any negative unintended consequences in other jurisdictions. This longitudinal cohort study is the first to evaluate the impact of menthol cigarette bans on smoking behaviour and smoking cessation among adult smokers in seven Canadian provinces.

\section{METHODS}

\section{Participants and sampling}

Data are from Wave 1 (2016) and Wave 2 (2018) of the ITC Four Country Smoking and Vaping (4CV) Survey. In brief, the ITC $4 \mathrm{CV}$ Survey retained participants from the original ITC Four Country Survey of nationally representative samples of adult smokers (aged 18+ years) in Australia, Canada, the UK and the USA (2002-2014) who met eligibility criteria, and recruited new participants who were current smokers, former smokers (quit $\leq 2$ years) or current vapers from country-specific panels.

Figure 1 presents the timeline of menthol cigarette bans in each of the seven provinces evaluated and pre-post ban survey dates. The ITC 4CV Wave 1 Survey was conducted in Canada from July to November 2016, before the implementation of menthol cigarette bans in seven provinces. The Wave 2 Survey was conducted from February to July 2018, after implementation of provincial menthol cigarette bans in Quebec, Ontario, Prince Edward Island, Newfoundland and Labrador; and a nationwide ban covering British Columbia, Saskatchewan and Manitoba (additional details in online supplemental file 1). This study included 2343 Canadian adult smokers who participated in Wave 1, with 1072 recontacted as smokers and 164 recontacted as quitters

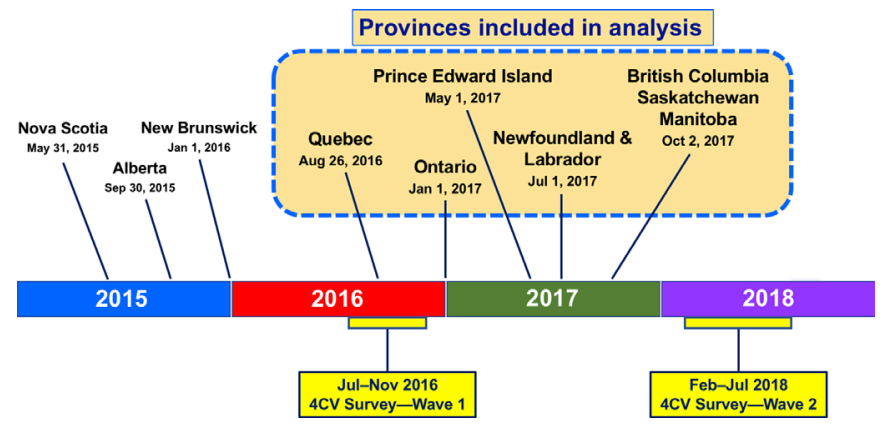

Figure 1 Implementation of menthol cigarette bans (at retail level) in Canada in relation to ITC Four Country Smoking and Vaping Wave 1 (2016) and Wave 2 (2018) Survey dates. at Wave 2. A cohort of 850 newly recruited adult smokers was also included at Wave 2. Sampling weights were calibrated to benchmarks from national surveys to ensure that data are representative of the adult smoker and vaper population in Canada. Data were collected online, and respondents were remunerated. Methodological details are described elsewhere ${ }^{21-25}$ and available online (http://www.itcproject.org/methods).

\section{Measures}

Pre-ban smoking status

Smokers were defined as those who had smoked at least 100 cigarettes in their lifetime and currently smoked cigarettes at least monthly. At Wave 1, smokers were asked whether they had a usual brand of cigarettes. Respondents were then asked to identify the flavour of their usual brand or the brand they last purchased. Respondents who selected 'tobacco and menthol' flavour were categorised as menthol smokers, and those who selected 'just tobacco' or 'tobacco and some other flavour' were categorised as non-menthol smokers.

\section{Post-ban smoking status}

At Wave 2, respondents were asked to identify the flavour of their usual cigarette brand or the brand they last purchased. Respondents were categorised into one of three types of post-ban product use for analyses: (1) currently not smoking, (2) currently smoking menthol cigarettes and (3) currently smoking non-menthol cigarettes.

\section{Post-ban purchase of menthol cigarettes}

Post-ban menthol smokers were asked to report where they last purchased menthol cigarettes for personal use. Figure 2 provides all response categories.

\section{Post-ban cessation behaviours}

Quit attempts were assessed by asking current smokers who reported ever making a quit attempt: 'In the last 18 months, have you tried to stop smoking?' Responses were coded as 'yes' and 'no'. Responses 'refused' and 'don't know' were excluded from analysis. Respondents who reported that they had currently quit smoking were also coded as 'yes' to having made a quit attempt.

Quit success was based on a composite measure of selfreported quitting behaviour and the length of time that respondents maintained their quit status. Successful quitters were defined as those who had currently quit or cut down to smoking less than monthly, while current smokers were defined as those who were still smoking at least monthly with or without making a previous quit attempt. Respondents were then further classified into three categories for post-ban quitting behaviour based on the length of time they remained quit: (1) post-ban quit (quit $\leq 6$ months at follow-up and were short-term quitters who stopped smoking after nationwide menthol ban), (2) post-ban remained quit (quit $>6$ months at follow-up and were long-term quitters who stopped smoking before the nationwide ban and remained quit) and (3) post-ban non-quit (those who were still currently smoking) (additional details in online supplemental file 1). Responses 'refused' and 'don't know' were excluded from analysis.

\section{Covariates}

Covariates measured at Wave 1 and included in all regression models were: sex, age, ethnicity, annual household income, education level, menthol smoking status, plans to quit smoking in next 6 months, Heaviness of Smoking Index (HSI; composite 

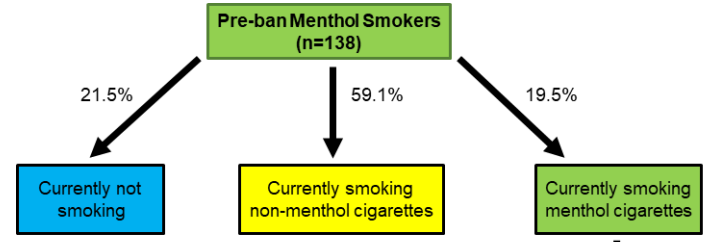

Post-ban smoking smoking

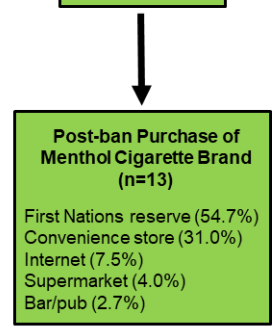

Note: Percent values in this figure are weighted estimates, and do not sum to $100 \%$ because of rounding

Figure 2 Post-ban transitions in smoking behaviour and sources of menthol cigarette purchase by menthol smokers.

measure of nicotine dependence that combines cigarettes smoked per day and time to first cigarette), ${ }^{26}$ time (number of months) of follow-up after implementation of menthol ban and time-insample (TIS). ${ }^{27}$ Table 1 provides grouping categories.

\section{Statistical analysis}

Data were analysed using SAS-callable SUDAAN V.11. Unweighted descriptive statistics were used to estimate sample characteristics. A longitudinal prospective analysis using weighted multivariable survey logistic regression models examined associations between pre-ban menthol smoking status and post-ban smoking behaviour and smoking cessation. Regression models used weighted data from Wave 1 smokers who were recontacted at Wave 2, controlling for the covariates (additional details in online supplemental file 1).

Regression models were conducted to examine associations between the frequency of pre-ban menthol cigarette use and four smoking cessation outcomes at follow-up: (1) quit attempts, (2) quit success (currently quit or cut down to smoking less than monthly), (3) short-term quit (quit $\leq 6$ months, after nationwide menthol ban) and (4) long-term quit (quit $>6$ months, before nationwide menthol ban and remained quit). All models controlled for demographics, intentions to quit, history of quitting, HSI, time of follow-up after menthol ban and TIS. The key comparison groups were: (1) overall menthol smokers versus non-menthol smokers, (2) daily menthol smokers versus daily non-menthol smokers and (3) non-daily menthol smokers versus non-daily non-menthol smokers.

\section{RESULTS}

\section{Sample characteristics}

The longitudinal analysis was based on 1236 respondents from seven provinces who completed both the Wave 1 and Wave 2 ITC 4CV Canada Surveys. Table 1 presents the sample characteristics. The majority of the sample were White and had plans to quit in next 6 months. Of the total sample, 1098 were nonmenthol smokers and 138 were menthol smokers. There was an even distribution of menthol and non-menthol smokers across all demographic and smoking-related behaviour groups at Wave 1 , except for a higher distribution of menthol smokers in the younger (18-24 and 25-39) age groups, and higher education group.

\section{Post-ban smoking behaviour}

Among pre-ban menthol smokers $(\mathrm{n}=138), 59.1 \%$ had switched to use of non-menthol cigarettes, $19.5 \%$ continued to use menthol cigarettes and $21.5 \%$ had quit smoking at follow-up (figure 2).

Among pre-ban non-menthol smokers ( $\mathrm{n}=1098), 84.9 \%$ continued to use non-menthol cigarettes, $1.1 \%$ had switched to use of menthol cigarettes and $14.0 \%$ had quit smoking at follow-up.

Overall, pre-ban menthol smokers were significantly more likely than pre-ban non-menthol smokers to continue using menthol cigarettes at follow-up. Pre-ban menthol smokers were less likely than pre-ban non-menthol smokers to report using non-menthol cigarettes at follow-up (table 2).

\section{Post-ban purchase of menthol cigarettes}

Of the 38 pre-ban menthol smokers who said they still smoked menthol cigarettes at follow-up, 13 reported a menthol cigarette brand as their last purchase $(36.1 \%, 95 \%$ CI 22.5 to 52.3$), 5$ reported a menthol 'replacement' brand $(6.9 \%$, 95\% CI 2.7 to 16.8 ) and 20 reported a non-menthol brand or indeterminate brand (57.0\%, 95\% CI 41.4 to 71.4 ). Among the 13 post-ban menthol smokers who reported a menthol cigarette brand as their last purchase, $54.7 \%$ (95\% CI 28.6 to 78.4) reported buying them from a First Nations reserve and 31.0\% (95\% CI 12.3 to 58.9 ) from convenience stores. Few smokers purchased menthol cigarettes from all other sources (range: $2.7 \%$ in bars/ pubs (95\% CI 0.2 to 26.5 ) to $7.5 \%$ by internet (95\% CI 0.7 to 48.4)) (figure 2).

\section{Post-ban smoking cessation behaviours}

Table 3 presents the post-ban findings for quit attempts, and quitting by key demographic variables (sex, age, ethnicity, income, education), intentions to quit, history of quitting, HSI, time of follow-up after menthol ban and TIS. The key predictor was menthol smokers versus non-menthol smokers.

\section{Quit attempts}

Menthol smokers were significantly more likely than nonmenthol smokers to attempt to quit at follow-up (adjusted OR $(\mathrm{aOR})=1.61 ; 95 \%$ CI 1.03 to 2.51$)$. Smokers who did not make a quit attempt before bans were less likely than those who made a pre-ban quit attempt to make a quit attempt at follow-up. Smokers with no plans to quit before bans were also less likely than those with plans to quit before bans to make a quit attempt at follow-up. Additionally, non-White smokers were more likely than White smokers to make a quit attempt at follow-up. Other demographics, pre-ban smoking behaviours, time of follow-up after menthol ban and TIS were not significant predictors (table 3).

\section{Quit success}

There was no significant difference in short-term quitting after the nationwide menthol ban between menthol smokers and nonmenthol smokers $(\mathrm{aOR}=1.30 ; 95 \%$ CI 0.56 to 3.01$)$.

Smokers with high income and those who did not report income were more likely than smokers with low income to be short-term quitters. Compared with smokers with lower nicotine dependence, those with higher nicotine dependence were less likely to be short-term quitters, and those who did not report on their dependence were more likely be short-term quitters. Other demographics, pre-ban smoking behaviours, time of 


\section{Original research}

Table 1 Characteristics of smokers participating in the ITC Four Country Smoking and Vaping Canada Survey at Wave 1 (2016) who were recontacted at Wave 2 (2018) $(\mathrm{N}=1236)$

\begin{tabular}{|c|c|c|c|c|}
\hline \multirow[b]{2}{*}{ Characteristic } & \multirow{2}{*}{$\begin{array}{l}\text { Total, } \mathrm{N}=1236 \\
\text { Unweighted } \mathrm{n}(\%)\end{array}$} & \multirow{2}{*}{$\begin{array}{l}\text { Menthol smokers, } \mathrm{n}=138 \\
\text { Unweighted } \mathrm{n}(\%)\end{array}$} & \multirow{2}{*}{$\begin{array}{l}\text { Non-menthol smokers, } \mathrm{n}=1098 \\
\text { Unweighted } \mathrm{n}(\%)\end{array}$} & \multirow{2}{*}{$\begin{array}{l}\text { Menthol vs non-menthol comparison } \\
\text { p-value }\end{array}$} \\
\hline & & & & \\
\hline \multicolumn{5}{|l|}{ Demographics } \\
\hline Female & $638(51.6)$ & $78(56.5)$ & $560(51.0)$ & 0.221 \\
\hline Male & $598(48.4)$ & $60(43.5)$ & $538(49.0)$ & \\
\hline \multicolumn{5}{|l|}{ Age group (years) } \\
\hline $40-54$ & $406(32.8)$ & $47(34.1)$ & $359(32.7)$ & \\
\hline $55+$ & $383(31.0)$ & $31(22.5)$ & $352(32.1)$ & \\
\hline \multicolumn{5}{|l|}{ Ethnicity } \\
\hline White & $1054(85.3)$ & $114(82.6)$ & $940(85.6)$ & 0.375 \\
\hline Non-White & $166(13.4)$ & $22(15.9)$ & $144(13.1)$ & \\
\hline Moderate (\$45 000-\$74 999) & $312(25.2)$ & $36(26.1)$ & $276(25.1)$ & \\
\hline High $(\geq \$ 75000)$ & $347(28.1)$ & $41(29.7)$ & $306(27.9)$ & \\
\hline Not reported & $92(7.4)$ & $9(6.5)$ & $83(7.6)$ & \\
\hline \multicolumn{5}{|l|}{ Education } \\
\hline Low (high school or less) & $355(28.7)$ & $32(23.2)$ & $323(29.4)$ & 0.009 \\
\hline $\begin{array}{l}\text { Moderate (trade school/community college/ } \\
\text { some university) }\end{array}$ & $553(44.7)$ & 55 (39.9) & $498(45.4)$ & \\
\hline High (university/post-graduate) & $321(26.0)$ & $50(36.2)$ & $271(24.7)$ & \\
\hline Not reported & $7(0.6)$ & $1(0.7)$ & $6(0.5)$ & \\
\hline \multicolumn{5}{|l|}{ Wave 1 predictors } \\
\hline HSI (mean) & $1114(2.3)$ & $997(2.3)$ & $117(2.2)$ & 0.446 \\
\hline First survey & $964(78.0)$ & $112(81.2)$ & $852(77.6)$ & 0.226 \\
\hline 2 surveys & $177(14.3)$ & $15(10.9)$ & $162(14.8)$ & \\
\hline$>2$ surveys & $95(7.7)$ & $11(8.0)$ & $84(7.7)$ & \\
\hline
\end{tabular}

HSI, Heaviness of Smoking Index.

Table 2 Associations between pre-ban menthol smoking status and post-ban smoking behaviour

\begin{tabular}{|c|c|c|c|c|c|c|}
\hline & \multicolumn{2}{|c|}{ Post-ban use of menthol cigarettes } & \multicolumn{2}{|c|}{ Post-ban use of non-menthol cigarettes } & \multicolumn{2}{|c|}{ Post-ban quit smoking } \\
\hline & $\%(95 \% \mathrm{Cl})$ & aOR $(95 \% \mathrm{Cl})$ & $\%(95 \% \mathrm{Cl})$ & aOR $(95 \% \mathrm{Cl})$ & $\%(95 \% \mathrm{Cl})$ & aOR $(95 \% \mathrm{Cl})$ \\
\hline \multicolumn{7}{|l|}{ Pre-ban smokers (overall) } \\
\hline Menthol smoker & 19.5 (13.2 to 27.7$)$ & $24.90(11.6 \text { to } 53.7)^{* * *}$ & $59.1(49.5$ to 68.0$)$ & $0.23(0.14 \text { to } 0.37)^{* * *}$ & 21.5 (14.4 to 30.8$)$ & 1.72 (0.98 to 3.01$)$ \\
\hline Non-menthol smoker & $1.1(0.6$ to 2.1$)$ & & $84.9(82.1$ to 87.3$)$ & & $14.0(11.7$ to 16.7$)$ & \\
\hline \multicolumn{7}{|l|}{ Pre-ban daily smokers } \\
\hline Menthol smoker & $21.0(13.8$ to 31.7$)$ & $29.2(10.9 \text { to } 77.8)^{* * *}$ & $58.1(47.7$ to 68.0$)$ & $0.17(0.10 \text { to } 0.30)^{\star * *}$ & $21.0(13.2$ to 31.6$)$ & $2.21(1.15 \text { to } 4.24)^{*}$ \\
\hline Menthol smoker & 13.1 (5.5 to 27.8$)$ & $43.25(7.67 \text { to } 244.0)^{* * *}$ & $63.7(43.0$ to 80.3$)$ & $0.63(0.24$ to 1.66$)$ & $23.3(10.7$ to 43.3$)$ & 0.65 (0.24 to 1.80$)$ \\
\hline Non-menthol smoker & $1.2(0.4$ to 3.6$)$ & & 73.7 (64.7 to 81.1$)$ & & 25.1 (17.8 to 34.1$)$ & \\
\hline $\begin{array}{l}\text { Significance levels: }{ }^{*} \mathrm{p}<0 \text {. } \\
\mathrm{aOR} \text {, adjusted } \mathrm{OR} ; \mathrm{Cl} \text {, con }\end{array}$ & $\begin{array}{l}p<0.001 \\
\text { interval. }\end{array}$ & & & & & \\
\hline
\end{tabular}


Table 3 Pre-ban predictors of smokers' post-ban quit attempts and quit success

\begin{tabular}{|c|c|c|c|}
\hline & Post-ban quit attempt & Post-ban quit & Post-ban remained quit \\
\hline & aOR $(95 \% \mathrm{Cl})$ & aOR $(95 \% \mathrm{Cl})$ & aOR $(95 \% \mathrm{Cl})$ \\
\hline \multicolumn{4}{|l|}{ Pre-ban menthol smoking status } \\
\hline Menthol smoker & $1.61(1.03 \text { to } 2.51)^{*}$ & 1.30 (0.56 to 3.01$)$ & $2.30(1.06 \text { to } 5.01)^{*}$ \\
\hline Non-menthol smoker & 1 & 1 & 1 \\
\hline \multicolumn{4}{|l|}{ Sex } \\
\hline Female & 0.90 (0.67 to 1.20$)$ & 0.78 (0.48 to 1.26$)$ & 0.69 (0.39 to 1.22 ) \\
\hline Male & 1 & 1 & 1 \\
\hline \multicolumn{4}{|l|}{ Age group (years) } \\
\hline $18-24$ & 1.33 (0.82 to 2.15$)$ & 0.93 (0.42 to 2.07$)$ & 0.79 (0.30 to 2.06 ) \\
\hline $25-39$ & 1.05 (0.68 to 1.62 ) & 1.89 (0.98 to 3.67 ) & 1.21 (0.50 to 2.94 ) \\
\hline $40-54$ & 0.79 (0.5 to 1.14$)$ & 0.57 (0.28 to 1.17$)$ & 0.99 (0.51 to 1.91$)$ \\
\hline $55+$ & 1 & 1 & 1 \\
\hline \multicolumn{4}{|l|}{ Ethnicity } \\
\hline Non-White & $1.77(1.10 \text { to } 2.85)^{*}$ & 1.47 (0.73 to 2.96$)$ & 0.61 (0.21 to 1.75$)$ \\
\hline Not reported & 1.58 (0.54 to 4.63$)$ & 1.67 (0.34 to 8.11$)$ & 2.40 (0.59 to 9.79$)$ \\
\hline White & 1 & 1 & 1 \\
\hline \multicolumn{4}{|l|}{ Household income } \\
\hline Low & 1 & 1 & 1 \\
\hline Moderate & 1.27 (0.87 to 1.86$)$ & 1.88 (0.94 to 3.79$)$ & 1.12 (0.52 to 2.39$)$ \\
\hline High & 1.28 (0.87 to 1.90$)$ & $2.11(1.07 \text { to } 4.14)^{*}$ & 1.38 (0.65 to 2.95$)$ \\
\hline Not reported & 1.00 (0.57 to 1.76 ) & $2.83(1.16 \text { to } 6.93)^{*}$ & 2.12 (0.76 to 5.91$)$ \\
\hline \multicolumn{4}{|l|}{ Education } \\
\hline Low & 1 & 1 & 1 \\
\hline Moderate & 1.05 (0.73 to 1.52 ) & 1.46 (0.75 to 2.83$)$ & 1.14 (0.51 to 2.52 ) \\
\hline High & $0.96(0.61$ to 1.49$)$ & 1.49 (0.68 to 3.26$)$ & 1.67 (0.71 to 3.94$)$ \\
\hline \multicolumn{4}{|l|}{ Pre-ban HSI } \\
\hline $0-3$ & 1 & 1 & 1 \\
\hline $4-6$ & 0.77 (0.53 to 1.12$)$ & $0.39(0.17 \text { to } 0.92)^{*}$ & 0.59 (0.28 to 1.24$)$ \\
\hline Not reported & 1.22 (0.70 to 2.12 ) & $2.88(1.46 \text { to } 5.66)^{*}$ & 1.88 (0.80 to 4.39$)$ \\
\hline \multicolumn{4}{|l|}{ Pre-ban intentions to quit in next 6 months } \\
\hline No & $0.50(0.35 \text { to } 0.70)^{* * *}$ & $0.80(0.40$ to 1.60$)$ & $0.53(0.23$ to 1.21$)$ \\
\hline Yes & 1 & 1 & 1 \\
\hline \multicolumn{4}{|l|}{ Pre-ban quit attempts } \\
\hline No & $0.26(0.19 \text { to } 0.35)^{* * *}$ & 0.60 (0.34 to 1.08$)$ & 0.56 (0.30 to 1.05$)$ \\
\hline Yes & 1 & 1 & 1 \\
\hline \multicolumn{4}{|l|}{ Time-in-sample } \\
\hline First survey & 0.81 (0.52 to 1.25$)$ & $0.50(0.25$ to 1.03$)$ & $0.53(0.23$ to 1.20$)$ \\
\hline 2 surveys & $0.75(0.40$ to 1.40$)$ & 1.18 (0.40 to 3.44$)$ & 0.34 (0.08 to 1.43$)$ \\
\hline$>2$ surveys & 1 & 1 & 1 \\
\hline Time of follow-up after implementation of menthol ban (months) & 1.02 (0.99 to 1.04$)$ & 0.98 (0.93 to 1.02$)$ & $1.02(0.96$ to 1.10$)$ \\
\hline
\end{tabular}

Significance levels: ${ }^{*} \mathrm{p}<0.05{ }^{* * *} \mathrm{p}<0.001$.

Sampling strata were incorporated into the survey logistic regression models to adjust for any potential survey design effects.

$\mathrm{aOR}$, adjusted $\mathrm{OR} ; \mathrm{Cl}$, confidence interval; $\mathrm{HSI}$, Heaviness of Smoking Index.

follow-up after menthol ban and TIS were not significant predictors (table 3).

Menthol smokers were significantly more likely than nonmenthol smokers to be long-term quitters who remained quit after the nationwide menthol ban $(\mathrm{aOR}=2.30 ; 95 \%$ CI 1.06 to 5.01). Demographics, pre-ban smoking behaviours, time of follow-up after menthol ban and TIS were not significant predictors (table 3).

\section{Comparison of Ontario versus six other provinces}

There were no significant differences in smoking cessation outcomes among menthol and non-menthol smokers in Ontario, compared with smokers in six other provinces (additional details in online supplemental file 2).
Associations between frequency of pre-ban menthol cigarette use and post-ban smoking cessation behaviours

Overall, pre-ban menthol smokers were significantly more likely than pre-ban non-menthol smokers to have made a quit attempt at follow-up (58.7\% vs 49.0\%, aOR $=1.61, \mathrm{p}<0.05)$, and to have long-term quit $(12.1 \%$ vs $5.9 \%, \mathrm{aOR}=2.30, \mathrm{p}<0.05)$. There were no significant differences in quit success at follow-up or short-term quitting after the nationwide menthol ban between pre-ban menthol and non-menthol smokers.

Among pre-ban daily smokers, daily menthol smokers were significantly more likely than daily non-menthol smokers to have made a quit attempt $(58.8 \%$ vs $47.0 \%, \mathrm{aOR}=1.88, \mathrm{p}<0.05)$, to have quit successfully $(21.0 \%$ vs $11.6 \%, \mathrm{aOR}=2.21, \mathrm{p}<0.05)$ and to have long-term quit $(12.7 \%$ vs $5.2 \%, \mathrm{aOR}=2.81$, 
$\mathrm{p}<0.05)$. There was no significant difference in short-term quitting after the nationwide menthol ban between daily menthol smokers and daily non-menthol smokers.

Among pre-ban non-daily smokers, there were no significant differences in quit attempts, quit success, and short-term and long-term quit between non-daily menthol smokers and nondaily non-menthol smokers.

\section{DISCUSSION}

Findings of this evaluation of the Canadian ban on menthol cigarettes augments and extends the evaluation of the menthol cigarette ban in Ontario to include six other provinces. ${ }^{15-18}$ We found that most menthol smokers continued using cigarettes after bans, with $59.1 \%$ of menthol smokers switching to nonmenthol cigarettes-higher than Chaiton et al $\mathrm{s}^{17}$ finding that $28.2 \%$ menthol smokers switched to non-menthol cigarettes after the menthol ban in Ontario.

We found that $19.5 \%$ of pre-ban menthol smokers continued to smoke menthol cigarettes after bans, with First Nations reserves as the most common source of post-ban menthol cigarette purchase, followed by convenience stores. Although a sizeable minority of pre-ban menthol smokers reported post-ban access to menthol cigarettes, they were still more likely to make a quit attempt compared with non-menthol smokers, which suggests that policy impact might have been even greater with strengthened enforcement. It is unclear how smokers were able to purchase menthol cigarettes at retail locations after bans. Previous studies have found high retailer compliance with menthol cigarette bans in Ontario, Alberta and Nova Scotia, ${ }^{28} 29$ and no evidence for increased seizures of illicit menthol or nonmenthol cigarettes after a menthol ban in Nova Scotia. ${ }^{30}$ Future studies should investigate possible gaps in post-ban compliance and enforcement, stockpiling behaviour or access to contraband products. It is possible that menthol smokers from provinces in close proximity to the USA could purchase menthol cigarettes across the border; however, a previous study from Ontario found no significant impact of proximity to the USA during the period of a provincial menthol ban and access to menthol cigarettes. ${ }^{16}$ Our study found that no menthol smokers reported purchase of menthol cigarettes outside the country after bans. Another possibility is that some menthol smokers may have reported post-ban purchase of redesigned menthol 'replacement' packs that use colour on the pack or in the brand name to convey menthollike qualities, as reported by previous studies in Alberta ${ }^{29}$ and Ontario. ${ }^{28}$ Few smokers reported post-ban purchase of menthol 'replacement' packs in the current study.

A 2020 study found that a substantial minority (14.6\%) of pre-ban menthol smokers in Ontario reported post-ban use of menthol flavour cards or additives, despite the lack of marketing for these products. ${ }^{31}$ Tobacco companies in the UK have also introduced new products that are exempt from the European Union menthol cigarette ban, including mentholflavoured infusion cards, filter tips and capsule cigarillos. ${ }^{32} 33$ The cigarette companies could also use existing technology for custom-mentholated cigarettes ${ }^{34}$ to continue adding menthol to cigarettes at below observable levels to reduce the negative sensations of smoking. ${ }^{356}$ This highlights the need for jurisdictions to consider banning menthol as an ingredient in cigarettes together with policies, such as tobacco plain packaging, cigarette filter regulations and bans on brand descriptors, that would prevent tobacco industry strategies to circumvent menthol bans.

We also found that menthol cigarette bans significantly increased reported quit attempts among menthol smokers. Our
Canada-wide findings replicate and extend previous research showing that menthol smokers were more likely to report quit attempts $^{161737}$ after a menthol cigarette ban in Ontario. In addition, we found that non-White smokers were more likely than White smokers to a make a quit attempt after bans. This has important public health and equity implications for countries such as the USA, where menthol cigarette use is substantially higher among African-Americans compared with other racial or ethnic groups. ${ }^{7838}$

Our finding that daily menthol smokers across seven provinces, covering $83 \%$ of the Canadian population, were significantly more likely than daily non-menthol smokers to have quit successfully at follow-up is consistent with the results of Chaiton et al's Ontario menthol ban study. ${ }^{16}$ Together, these findings suggest that the heaviest smokers were most favourably affected by the menthol ban and highlights the importance of smoking cessation services to help menthol smokers to stay quit.

We also examined the possible impact of menthol bans on staying quit—an outcome that, to our knowledge, has not been examined before. We found that menthol smokers were significantly more likely than non-menthol smokers to be long-term quitters who stopped smoking before the nationwide ban and remained quit-this pattern of findings was also observed between daily menthol smokers compared with daily non-menthol smokers, but not for non-daily menthol smokers compared with non-daily non-menthol smokers. This suggests that menthol cigarette bans may help to prevent relapse among those who have quit smoking menthol cigarettes, especially the heaviest menthol smokers, and may facilitate successful longterm smoking cessation.

The public health benefits of a menthol cigarette ban are likely to be even greater in countries such as the USA, where the prevalence of menthol cigarette use and product sales are substantially higher relative to rates observed in Canada prior to bans $(-38.0 \%$ menthol smoking prevalence in the USA vs $2.0 \%$ in Canada; $~ 35.0 \%$ menthol cigarette sales in the USA vs $5.0 \%$ in Canada). ${ }^{39-42}$ Indeed, a SimSmoke modelling study estimated that if the USA had implemented a menthol cigarette ban in 2011, between 323000 and 633000 deaths would be averted by 2050 , with nearly one-third of the averted deaths being among Blacks. ${ }^{13}$

This study has some limitations. First, variation in the time of implementation of provincial/federal menthol cigarette bans across the seven provinces in relation to ITC 4CV Survey dates did not allow for direct comparison of short-term versus longterm policy effects. However, our study provides important evidence on the longer-term effects of menthol cigarette bans as we assessed policy impact across a broad time range in seven provinces that goes beyond that covered in previous studies from Ontario. ${ }^{16-18}$ Second, our post-ban survey was conducted between February and July 2018, which means that some respondents may have reported quit attempts (made in the last 18 months) before menthol bans came into effect. Third, we used smokers' self-reports of cigarette brand they last purchased to measure post-ban menthol smoking status, which may lead to potential misclassification at follow-up. Fourth, our sample of non-menthol smokers may include occasional menthol smokers as our survey questions do not allow for distinction between these two user groups, and this could influence effect sizes. Fifth, it is possible that some respondents who reported use of non-menthol cigarettes at follow-up were using menthol capsule cigarettes, which is not measured in our survey. Finally, we were unable to determine what proportion of menthol cigarettes that smokers purchased after bans were contraband. Given the small 
sample sizes of recontacted menthol smokers who reported on where they purchased menthol cigarettes before and after bans, we were unable to assess whether there were any significant prepost ban changes in menthol cigarette purchase in each of the individual sources, and whether there were any differences by province. Nevertheless, our study found that $57.0 \%$ of pre-ban menthol smokers who said they still smoked menthol cigarettes at follow-up reported a non-menthol cigarette brand as their last purchase; and of those post-ban menthol smokers who reported purchase of a menthol cigarette brand, $54.7 \%$ said that they bought them from a First Nations reserve. Taken together, this suggests a relatively low rate of post-ban illicit menthol cigarette purchase, despite the availability from First Nations reserves.

\section{CONCLUSION}

A menthol cigarette ban in Canada significantly increased quit attempts and quit success among menthol smokers compared with non-menthol smokers, and prevented relapse among those who had quit smoking menthol cigarettes before the ban, particularly among the heaviest smokers. A majority of pre-ban menthol smokers were still smoking, which illustrates the powerful addictiveness of nicotine delivery from cigarettes.

\section{What this paper adds}

\section{What is already known on this subject}

- Few population-based studies have evaluated the actual effects of implemented menthol cigarette bans to date. Studies from Ontario, Canada provide evidence that a menthol cigarette ban promotes smoking cessation among menthol smokers, with minimal substitution to other products.

\section{What this paper adds}

- We evaluated the impact of menthol cigarette bans on smoking behaviour and smoking cessation across seven provinces covering $83 \%$ of the Canadian population.

- After a ban on menthol cigarettes in Canada, most menthol smokers switched to non-menthol cigarettes. However, the menthol cigarette ban significantly increased quit attempts and quit success among daily menthol smokers compared with daily non-menthol smokers, and prevented relapse among menthol smokers who had quit before the ban.

- Findings of this extensive evaluation study in Canada suggest that a menthol ban would lead to substantial public health benefits at the population-level in other jurisdictions, notably in the USA, where prevalence of menthol cigarette use is much higher, especially among African Americans.

\section{Acknowledgements The authors would like to thank Janine Ouimet and Nadia Martin for project management of the International Tobacco Control Four Country Smoking and Vaping Survey.}

Contributors GTF and JC-H contributed to conceptualisation and study design. JC-H wrote the original draft manuscript and prepared the final version. LVC and GTF contributed to writing. GM conducted the data analysis. GM, JC-H and GTF contributed to data interpretation. GTF, LVC, GM, KMC, AH, RJO and ACKQ contributed to review and editing. All authors gave final approval of the version to be published.

Funding The International Tobacco Control Four Country Smoking and Vaping Survey was supported by grants from the US National Cancer Institute (P01 CA200512), the Canadian Institutes of Health Research (FDN-148477) and the National Health and Medical Research Council of Australia (APP 1106451). Additional support was provided to GTF from a Senior Investigator Award from the Ontario Institute for Cancer Research. RJO and AH were supported by a Tobacco Centres of Regulatory Science US National Cancer Institute grant (U54 CA238110).
Competing interests GTF has served as an expert witness on behalf of governments in litigation involving the tobacco industry. KMC has served as a paid expert witness in litigation filed against cigarette manufacturers.

Patient consent for publication Not required.

Ethics approval Research ethics approval (ORE\#20803/30709) for the ITC 4CV Canada Survey was obtained from the Office of Research Ethics, University of Waterloo, Canada.

Provenance and peer review Not commissioned; externally peer reviewed.

Data availability statement Data are available upon reasonable request. All data relevant to the study are included in the article or uploaded as supplementary information.

Open access This is an open access article distributed in accordance with the Creative Commons Attribution Non Commercial (CC BY-NC 4.0) license, which permits others to distribute, remix, adapt, build upon this work non-commercially, and license their derivative works on different terms, provided the original work is properly cited, appropriate credit is given, any changes made indicated, and the use is non-commercial. See: http://creativecommons.org/licenses/by-nc/4.0/.

\section{ORCID iDs}

Janet Chung-Hall http://orcid.org/0000-0002-9139-8100

Geoffrey T Fong http://orcid.org/0000-0001-9098-6472

K Michael Cummings http://orcid.org/0000-0002-7103-7017

Anne C K Quah http://orcid.org/0000-0002-5303-8884

Lorraine V Craig http://orcid.org/0000-0001-5269-1817

\section{REFERENCES}

1 Reid J. A history of mentholated cigarettes: "This Spud's for you". Phillip Morris. Legacy Tobacco Documents Library. Bates No. 2081595850/5863, 1993

2 Tobacco Products Scientific Advisory Committee. Menthol cigarettes and public health: review of the scientific evidence and recommendations. Rockville, MD: US Department of Health and Human Services, Food and Drug Administration, 2011. https:// wayback.archiveit.org/7993/20170405201731/https://www.fda.gov/downloads/ AdvisoryCommittees/CommitteesMeetingMaterials/TobaccoProductsScientificAdvisor yCommittee/UCM269697.pdf

3 World Health Organization. Case studies for regulatory approaches to tobacco products: menthol in tobacco products. Geneva: World Health Organization, 2018. https://www.who.int/tobacco/publications/prod_regulation/case-studies-mentholtobacco-products/en/

4 Ahijevych K, Garrett BE. Menthol pharmacology and its potential impact on cigarette smoking behavior. Nicotine Tob Res 2004;6 Suppl 1:17-28.

5 Ferris Wayne G, Connolly GN, Ferris G. Application, function, and effects of menthol in cigarettes: a survey of tobacco industry documents. Nicotine Tob Res 2004;6 Suppl 1:S43-54.

6 Cohn AM, Rose SW, llakkuvan V, et al. Harm perceptions of menthol and nonmenthol cigarettes differ by brand, race/ethnicity, and gender in US adult smokers: results from PATH Wave 1. Nicotine Tob Res 2019;21:439-49.

7 Villanti AC, Mowery PD, Delnevo CD, et al. Changes in the prevalence and correlates of menthol cigarette use in the USA, 2004-2014. Tob Control 2016;25:ii14-20.

8 U.S. Food and Drug Administration. Preliminary scientific evaluation of the possible public health effects of menthol versus nonmenthol cigarettes. Silver Spring, MD: Center for Tobacco Products, Food and Drug Administration, 2013. https://permanent. fdlp.gov/gpo39032/Preliminary\%20Scientific\%20Evaluation\%20Menthol\%20508\% 20reduced.pdf

9 World Health Organization. Advisory note: banning menthol in tobacco products: WHO Study Group on tobacco product regulation (TobReg). Geneva: World Health Organization, 2016. https://www.who.int/tobacco/publications/prod_regulation/ menthol-advisory-note/en/

10 Canadian Cancer Society. Overview summary of federal/provincial/territorial tobacco control legislation in Canada, 2017. Available: http://convio.cancer.ca/documents/ Legislative_Overview-Tobacco_Control-F-P-T-2017-final.pdf [Accessed 03 Mar 2021].

11 Government of Canada. Order amending the schedule of the tobacco act (menthol), 2017. Available: http://www.gazette.gc.ca/rp-pr/p2/2017/2017-04-05/html/sordors45-eng.php

12 Cadham CJ, Sanchez-Romero LM, Fleischer NL, et al. The actual and anticipated effects of a menthol cigarette ban: a scoping review. BMC Public Health 2020;20:1055

13 Levy DT, Pearson JL, Villanti AC, et al. Modeling the future effects of a menthol ban on smoking prevalence and smoking-attributable deaths in the United States. Am J Public Health 2011;101:1236-40.

14 Bold KW, Jatlow P, Fucito LM, et al. Evaluating the effect of switching to non-menthol cigarettes among current menthol smokers: an empirical study of a potential ban of characterising menthol flavour in cigarettes. Tob Control 2020;29:624-30.

15 Chaiton M, Schwartz R, Shuldiner J, et al. Evaluating a real world ban on menthol cigarettes: an interrupted time-series analysis of sales. Nicotine Tob Res 2020;22:576-9. 
16 Chaiton MO, Nicolau I, Schwartz R, et al. Ban on menthol-flavoured tobacco products predicts cigarette cessation at 1 year: a population cohort study. Tob Control 2020;29:tobaccocontrol-2018-054841--2017.

17 Chaiton M, Schwartz R, Cohen JE, et al. Association of Ontario's ban on menthol cigarettes with smoking behavior 1 month after implementation. JAMA Intern Med 2018:178:710-1.

18 Chaiton M, Papadhima I, Schwartz R, et al. Product substitution after a real world menthol ban: a cohort study. Tob Regul Sci 2020;6:205-12.

19 Chandra S, Chaloupka FJ. Seasonality in cigarette sales: patterns and implications for tobacco control. Tob Control 2003;12:105-7.

20 Chandra S, Gitchell JG, Shiffman S. Seasonality in sales of nicotine replacement therapies: patterns and implications for tobacco control. Nicotine Tob Res 2011;13:395-8.

21 Fong GT, Cummings KM, Borland R, et al. The conceptual framework of the International Tobacco Control (ITC) policy evaluation project. Tob Control 2006;15 Suppl 3:iii3-11.

22 Thompson ME, Fong GT, Hammond D, et al. Methods of the International Tobacco Control (ITC) Four Country Survey. Tob Control 2006;15 Suppl 3:iii12-18.

23 Thompson ME, Fong GT, Boudreau C, et al. Methods of the ITC Four Country Smoking and Vaping Survey, Wave 1 (2016). Addiction 2019;114 Suppl 1:6-14.

24 ITC Project. ITC Four Country Smoking and Vaping Survey, Wave 1 (2016) technical report. Waterloo, Ontario, Canada; Charleston, South Carolina, United States; Melbourne, Australia; London, United Kingdom, 2018. https://itcproject.org/methods/ technical-reports/itc-four-country-smoking-and-vaping-survey-4cv1-technical-reportwave-1-2016-november-2018/

25 ITC Project. ITC Four Country Smoking and Vaping Survey, Wave 2 (2018) technical report. Waterloo, Ontario, Canada; Charleston, South Carolina, United States; Melbourne, Australia: the University of Queensland, Australia; London, United Kingdom, 2020. https://itcproject.org/methods/technical-reports/itc-four-countrysmoking-and-vaping-survey-wave-2-4cv2-technical-report/

26 Heatherton TF, Kozlowski LT, Frecker RC, et al. Measuring the heaviness of smoking: using self-reported time to the first cigarette of the day and number of cigarettes smoked per day. Br J Addict 1989;84:791-800.

27 ITC Project. Comparing policy measures across multiple ITC countries: adjusting for time-in-sample. Waterloo, 2011. Available: https://itcproject.org/methods/technicalreports/comparing-policy-measures-across-multiple-itc-countries-adjusting-timesample/ [Accessed 03 Mar 2021].
28 Borland T, D'Souza SA, O'Connor S, et al. Is blue the new green? Repackaging menthol cigarettes in response to a flavour ban in Ontario, Canada. Tob Control 2019;28:e7-12.

29 Brown J, DeAtley T, Welding K, et al. Tobacco industry response to menthol cigarette bans in Alberta and Nova Scotia, Canada. Tob Control 2017;26:e71-4.

30 Stoklosa M. No surge in illicit cigarettes after implementation of menthol ban in Nova Scotia. Tob Control 2019;28:702-4

31 Chaiton MO, Schwartz R, Cohen JE, et al. The use of flavour cards and other additives after a menthol ban in Canada. Tob Control 2020. doi:10.1136/ tobaccocontrol-2020-055698. [Epub ahead of print: 24 Jul 2020].

32 Hefler M. Worldwide news and Comment. Tob Control 2020;29:127-30.

33 Hiscock R, Silver K, Zatoński M, et al. Tobacco industry tactics to circumvent and undermine the menthol cigarette ban in the UK. Tob Control 2020;29:tobaccocontrol-2020-055769-142

34 MacGregor IC, Stanfill SB, Gordon SM, et al. Custom mentholation of commercial cigarettes for research purposes. Toxicol Rep 2014;1:1068-75.

35 Yerger VB, McCandless PM. Menthol sensory qualities and smoking topography: a review of tobacco industry documents. Tob Control 2011;20 Suppl 2:ii37-43.

36 Ai J, Taylor KM, Lisko JG, et al. Menthol levels in cigarettes from eight manufacturers. Tob Control 2018;27:335-6.

37 Soule EK, Chaiton M, Zhang B, et al. Menthol cigarette smoker reactions to an implemented menthol cigarette ban. Tob Regul Sci 2019;5:50-64.

38 Delnevo CD, Ganz O, Goodwin RD. Banning menthol cigarettes: a social justice issue long overdue. Nicotine Tob Res 2020;22:1673-5.

39 Nahhas GJ, Brink S, O'Connor RR, et al. Cigarette brand preferences of adolescent and adult smokers in the United States, 2013-2014. Tob Regul Sci 2019;5:410-30.

40 Delnevo CD, Giovenco DP, Villanti AC. Assessment of menthol and nonmenthol cigarette consumption in the US, 2000 to 2018. JAMA Netw Open 2020;3:e2013601.

41 Bird Y, May J, Nwankwo C, et al. Prevalence and characteristics of flavoured tobacco use among students in grades 10 through 12: a national cross-sectional study in Canada, 2012-2013. Tob Induc Dis 2017;15:20.

42 Government of Canada. Canadian Tobacco Alcohol and Drugs (CTADS): 2015 summary. Available: https://www.canada.ca/en/health-canada/services/canadiantobacco-alcohol-drugs-survey/2015-summary.html [Accessed 03 Mar 2021]. 